Keith Doubt

\section{Through the Window: Kinship and Elopement in Bosnia-Herzegovina}

Budapest - New York: Central European University Press, 2014, 176 str.

DOI: 10.11567/met.31.2.5

Nakon knjige Sociologija nakon Bosne iz 2003., sredinom 2014. pojavila se nova knjiga Keitha Doubta, profesora s Odsjeka za sociologiju na Sveučilištu Wittenberg (Ohio, SAD), znakovita naslova Through the Window: Kinship and Elopement in Bosnia-Herzegovina. Knjiga je podijeljena na poglavlja: The Study of Elopement, The Liminality of Elopement, An Extraordinary Elopement, Habitus in Bosnia, Deciding in a Blink, The Secret and Elopement, Elopement and Ego-Identity, The Risk of Foreclosure in the Arranged Marriage, Family Folklore and Elopement, Affinal Relations after Elopement, Bosnia's Kin in Turkey, Balkan Ethnology, Bosnian Folk, Ethnicity and Nationality i Accounting for Bosnian Culture.

Ovom knjigom Doubt je otvorio, i to vrlo izazovno i primamljivo, jedan sociološki "prozor « kroz koji možemo ne samo iskočiti nego istodobno i uskočiti u jedan svijet, prividno zaboravljen i poprilično zanemaren, ali svijet istinskoga i osjećajnoga, i na individualnoj i na društvenoj razini. To je svijet bosanske autentične kulture, tj. kulturni svijet bosanske žene. Iako su središnja tema i pitanja kulturni obrasci koji se odnose na sklapanje braka, i to kroz posebnu kulturnu i društvenu pojavu zvanu »bijeg djevojke«, kada ona odluči u tajnosti "pobjeći i i udati se za nekog muškarca, a u Bosni bi to često bilo tako što bi ona izašla ili, kako se to $u$ narodu kaže, »iskočila kroz prozor «, u knjizi su najviše naglašeni elementi implicitne kulture. To su one najskrivenije, ali i najmoćnije sastavnice kulture do kojih možemo doći samo posredno, kroz analizu nekih vidljivih, pojavnih kulturnih obrazaca, što autor ovdje i čini. Upravo zbog toga posebno naglašava da ova knjiga ne govori o ratu, zločinu, genocidu ili suicidu, nego o nečemu što ima vitalno značenje za samo društvo, o nečemu što nije uništeno $u$ ratu te je prisutno i danas. Knjiga se bavi najosjetljivijim i najranjivijim komponentama kulture, ali s druge strane i najotpornijim elementima koji se ne mogu potrošiti u vremenu.

Životne pojave o kojima je riječ u knjizi, kao što su krađa djevojke i bijeg radi udaje, imaju ono što Doubt naziva prepoznatljivom kulturnom osobitošću. Autorov je pristup vrlo zanimljiv i značajan jer na te pojave ne gleda kao na devijacije ili odstupanja od tzv. normalnog stanja, već ih promatra kao nešto autentično i posebno u izgradnji identiteta žene i njezina odnosa s društvom. Osim toga posebno naglašava da se fenomen o kojem piše ne može izjednačiti sa slučajevima sklapanja braka otmicom djevojke. Bijeg nije otmica. On je svjesna, namjerna odluka i voljni čin kojim se iskazuje stav, i to stav pojedinca, točnije mlade žene. Važno je što razlikuje otmicu i bijeg na etičkoj razini. Bijeg je ustvari prelazak iz jednog stadija života u drugi, ali to nije bijeg od nečega, to je bijeg $i z$ nečega $u$ nešto novo, iz staroga u novi život, i to zbog samoga života i njegovih vrednota.

Istražujući norme sklapanja braka muslimanskih, pravoslavnih i ka- 
toličkih djevojaka u Bosni, autor ističe da je bijeg istovremeno i smisleni događaj i tajna. Ta je tajna za njega mnogo dublja nego što se čini. To nije samo tajenje nečega što se planira učiniti, nego izvire iz najveće dubine djevojačke duše, iz najtankoćutnijeg sloja njezine modalne ličnosti u kojoj se krije svojevrsni DNK našega duhovnog bića. Autor nas kroz vanjske, dominantno sociološke analize uspješno dovodi do toga svojevrsnoga genetskog zapisa duhovnosti. Usto napominje da valja razlikovati fiktivni bijeg od stvarnoga, koji je jedini istinski $\mathrm{i}$ istinit. Bijeg je čarobna stvar i emocionalno je dojmljiv te se može shvatiti i bez razumijevanja najvažnijih determinanti narodne kulture i obiteljskog folklora. Autor posebnim dijelom svoga istraživačkoga habitusa veoma lucidno zapaža da su priče koje su $\mathrm{mu}$ ispitanici ispričali ustvari najveće obiteljske dragocjenosti koje se dijele s drugima, a sadržavaju i fikciju i stvarnost te su kao takve potvrda samoaktualizacije osobnosti. Taj skladni odnos fikcije i stvarnosti zaista bolje može uočiti neki istraživač koji to, uvjetno rečeno, promatra sa strane i koji sam nije pripadnik te kulture, ali ipak je može analizirati iznutra.

Osim što ga promatra s kulturnoantropološkoga i etnološkog stajališta, autor predmet kojim se bavi smješta u neke od najznačajnijih socioloških koncepata i promišljanja. Govoreći o fenomenu bijega djevojke kroz teorijski koncept habitusa P. Bourdieua, ustvari govori o utjecaju tog fenomena na stvaranje $t z v$. modalne ličnosti. Tako razumijevanje bijega i svega povezanoga s njim čini jasnijim najsitnije, a time i najvažnije niti društvene strukture i stratifikacije. Posebnu po- zornost pridaje »donošenju odluke u trenu«. I zaista, ideja bijega nešto je što se javi u trenu, što se u izvornoj kulturi bosanske duhovne geografije označuje kratko i jasno kao »sudbina«. Bijeg karakterizira i kao transetnički fenomen jer on nije svojstven samo jednoj etničkoj grupi u Bosni. Sve to ilustrira i kvantitativnim statističkim pokazateljima. Kulturni obrazac stupanja u brak koji se zove »bijeg djevojke« razmatra i iz kuta Eriksonove teorije socijalnog razvoja, pri čemu posebno naglašava ulogu bijega u izgradnji ego-identiteta žene. Bijeg je u osnovi jačanja identiteta žene te njezina osjećaja vlastite vrijednosti i produktivnosti.

Sljedeća je bitna kulturno-antropološka dimenzija Doubtova opisa i prikaza individualnih osobnih iskustava njegovih ispitanika isticanje lakoće humora te osebujne karikaturalnosti u iskazima ispitanika kao i njihova razumijevanja i prihvaćanja sudbine. To ističe kao specifičnost bosanske kulture koja se ogleda u tome da se i najvažnije i najsudbonosnije odluke $\mathrm{u}$ životu pojednostavnjuju i humorom olakšavaju. Autor i sebe i čitatelje pita što je mladi par nakon sklapanja braka koji se dogovori u trenu, u treptaju oka, duše i srca. Jesu li su oni poznanici, prijatelji, ljubavnici, supružnici? Mogli bismo odgovoriti da oni nisu nijedno od toga pojedinačno, ali jesu sve to zajedno.

Svojim sociološkim analizama i uvidima autor upozorava i na neke, uvjetno rečeno, površnosti, pa i nepreciznosti u značajnim istraživanjima koja su provodili Tone Bringa, William Lockwood i Milenko Filipović, i to osobito kad je riječ o učestalosti bijega kod svih triju etničkih skupina, a 
ne samo kod Bošnjaka, te pitanju srodstva, $\mathrm{i}$ to $\mathrm{u}$ iskazima ispitanika, ali i $\mathrm{u}$ kvantitativnim statističkim pokazateljima. To je posebno vidljivo u shvaćanju srodstva i načina društvenog organiziranja. U tom smislu, ističe autor, svi dijele zajedničke elemente nasljeđa koji su unutarnji, domaći. Njegovo integriranje kvalitativnog i kvantitativnog pristupa ovdje je posebno važno i znanstveno opravdano.

Poglavlje koje govori o bosanskom rodu u Turskoj može biti jako dobra osnova za istraživanje fenomena bosanskog roda i srodstva kod brojnih Bosanaca koji su $\mathrm{u}$ ratu emigrirali $\mathrm{u}$ zapadne zemlje, osobito ako se obrati pozornost na to da, kako autor primjećuje, Bošnjaci u Turskoj imaju jak osjećaj identiteta, dok su istovremeno Bošnjaci u BiH dijelom čudno upetljani u tursku kulturu.

Na kraju knjige autor prelazi s prikaza jednog tako individualnog čina kao što je ulazak u brak putem bijega u područje suvremenih bosanskih društvenih problema koji se tiču etničnosti i nacionalnosti. To je u skladu s ciljevima koje je postavio na početku knjige: razmotriti obrazac stupanja u brak koji se zove »bijeg djevojke« iz kuta Eriksonove teorije socijalnog razvoja, analizirati fenomene kao što su prijateljstvo i kumstvo te srodstvo do kojega dolazi ženidbom i udajom i otvoriti pitanje što se s tim obrascima dogodilo u razdoblju ratnih raza- ranja na svim poljima. Ovo poglavlje pokazuje da mnoge zamišljene, imaginarne, kolektivne i počesto opasne percepcije koje gradi agresivna politika, pa i nekultura kolektiviteta, zaista gube snagu i njihova se oštrica tupi kada se »spuste « u svakidašnji i iskonski život.

Ova je knjiga svojevrsni zapis o dijelu autentičnog života koji nosi biljeg pojedinačnoga, posebnoga, tankoćutno osobnoga, ali istovremeno i karakteristike općega, zajedničkoga, kulturno-povijesnoga. Osobni biljezi i opće karakteristike neprestano se prožimaju i pojačavaju pokazujući nam tako određene kulturne apstrakcije jednoga bosanskog prostora i vremena. Kroz pojedinačno i partikularno rasvjetljavaju se društveni procesi i pojave kroz koje su nastajali i nestajali različiti elementi društvenog života, tj. života pojedinih etničkih i kulturnih zajednica. Na život i kulturu o kojima piše Doubt palo je mnogo ideološke i političke prašine. On nam ovom knjigom uvelike pomaže da tu prašinu obrišemo. Zato se ona može preporučiti svima koji se bave bosanskim društvom i kulturom, kulturnim antropolozima i etnolozima, sociolozima, etnopedagozima i studentima, kao i svima drugima koji žele zaviriti u svijet posebnoga mjesta koje se zove Bosnom.

\section{Adnan Tufekčić}

Filozofski fakultet Univerziteta u Tuzli, Tuzla 